E.L.U.A. 2, 1984, págs. 233-250

\title{
¿ES POSIBLE UNA «HISTORIA DE LAS IDEAS LINGÜÍSTICAS EN ESPAÑA»?
}

\author{
FRANCISCO ABAD NEBOT \\ (Universidad Nacional de Educación a Distancia. Madrid)
}

\begin{abstract}
"Que al par de los nombres de Fr. Luis de León, Ercilla, Cervantes, Lope, Calderón, Tirso y Quevedo, suenen de nuevo con aplauso, entre propios y extraños como sonaban en mejores tiempos, los de Lulio, Vives, Fox, Vallés, Gómez Pereira, Vázquez, Molina, Suárez, Domingo de Soto, Ángel Manrique, Isaac Cardoso, Caramuel y tantos otros».
\end{abstract}

(Gumersindo Laverde)

Estas palabras de quien fue un poco maestro de Menéndez Pelayo expresan bien su deseo de que fuesen conocidos los sabios españoles como son conocidos y celebrados - dice- nuestros autores literarios. Será asi loable proclama, la tarea de avivar su memoria.

Tal tarea la delinearia y cumpliría en una parte - como es sabido- el propio don Marcelino, que con su obra gigantesca no sólo es el creador de la historiografía de la literatura española, sino el de la de nuestro pensamiento '.

Don Marcelino está pidiendo a gritos un estudio que ordene, sintetice y evalúe sus contribuciones técnicas a la historia de la filosofía, de la ciencia y de las letras hispanas. 
La crítica subraya ahora que la llamada polémica de la ciencia española sólo sirvió a Menéndez Pelayo para poner de manifiesto su mentalidad conservadora, casticista y clerical, pero la verdad es que entonces ya delineó el polígrafo santanderino un programa de estudio de la historia de las ideas en España y trazó un inventario bibliográfico, si bien con errores de dato e interpretativos.

Queda, nos parece, ese programa de estudios, que para reparar la ignorancia respecto de la historia científica y aun literaria española deberá llevar a cabo, en primer término, monografías bibliográficas, y a continuación otras expositivo-críticas sobre autores o temas particulares. En efecto, un inventario bibliográfico aporta los primeros datos situadores de la «historia externa" del proceso intelectual de que se trate; don Marcelino pedía — por ejemplo- Diccionarios bibliográficos de "estéticos, preceptistas, criticos e historiadores de la literatura», de humanistas, etc. Él en concreto trazó una nómina de teorizadores de temas lingüísticos en el mencionado Inventario de La ciencia española, y luego 10 mismo volvería a ser hecho (de resultas de un certamen público convocado por la Academia) por el Conde de la Viñaza ${ }^{2}$; unos quince años más tarde, por tanto, del deseo de Menéndez Pelayo, se cumplía respecto a los gramáticos españoles, y en un catálogo que luego no ha sido mejorado, completado y continuado ${ }^{3}$.

El programa de estudio acerca de la historia de las ideas en España dibujado por Menéndez Pelayo -absolutamente vigente hoy-supone en su segundo paso el análisis y juicio de cada autor, de sus doctrinas, espíritu y significación histórica; es tarea de críticos y ya no sólo de bibliófilos y bibliógrafos. Para ello habrán de tratarse los grandes pensadores y las escuelas a cuyo frente se hallan: Averroes y el averroismo, Maimónides y el maimonismo, Vives o Suárez y el vivismo o suarismo..., así como los sabios que personifican grandes fases en la vida intelectual de la Peninsula: Alfonso el Sabio, Nebrija, Feijoo y Jovellanos, etc.

En esta secuencia de etapas de estudio queda por último - y como es lógico- trazar, con el apoyo bibliográfico y analítico-crítico ya alcanzado, la historia efectiva de la ciencia española en sus diferentes ramas.

Los trabajos para la reconstrucción e interpretación de la historia de la ciencia y del pensamiento español cuentan hoy con más de una iniciativa de aliento, en concreto por lo que se refiere a la filosofía y a la

2 La Viñaza, 1893.

Don Marcelino inicia su nómina de lingüistas del casteliano no con Nebrija, sino con los Refranes que dizen las viejas tras el fuego de Santillana. 
ciencia natural: Ios nombres de José María López Piñero, Victor Navarro, Eugenio Portela, del desaparecido José Maria Millás Vallicrosa, de José Luis Abellán, incluso también en este terreno el de Ferrater (por muchos artículos de su Diccionario), y otros más, no pueden citarse en vano. Nada parecido ocurre para la historia de las ideas lingüísticas, donde distintos nombres de interés están pasando casi completamente desapercibidos, otros tantos errores alcanzan envidiable fortuna oral e impresa, e incluso las más grandes figuras carecen de monografías de conjunto -dicho sea todo esto, desde luego, en primer lugar como autocrítica.

Distinguimos en la Historia de las ideas lingüisticas como disciplina una perspectiva interna y otra externa, esto es, historia interna e historia externa. La primera se habrá de acupar lógicamente del hacerse de la teoría, de cómo se ha pasado y se pasa de unas categorizaciones o conceptuaciones a otras; es algo dificil y sobre lo que apenas se hacen indicaciones. Por igual creemos que la historia interna de las ideas lingüisticas ha de ser sensible para tratar de las manifestaciones idiomáticas - sobre la renovación y crecimiento del vocabulario, por ejemplo- y de la manifestación de ideales de estilo que se encuentran en los mismos escritores, en preceptistas, etc.; desde luego también los gramáticos hacen muchas veces observaciones de estilo o métricas.

Historia "externa" de las ideas lingüísticas es - como puede suponerse- historia cultural de las mismas, de sus raices y formas: por qué Antonio de Nebrija o Andrés Bello escribieron sus gramáticas, en qué sentido la del segundo es una obra ilustrado-romántica, etc.

De acuerdo con esto, en fin, la historia de las doctrinas lingüisticas diluye una de sus fronteras con la de la lengua literaria, ya que en la base de los usos de los autores se encuentran su conciencia idiomática y su ideal de estilo; dicho de otra manera, la elocución respectiva de cada uno está ligada con su saber y su querer ser lingüisticos ${ }^{4}$. Junto, además, con la historia interna del sistema -lo que para entendernos podemos llamar gramática histórica-, las del idioma literario y de las concepciones lingüísticas dan lugar a la «Historia de la lengua» en cuanto disciplina diacrónica e integrada 5 .

4 Así una obra como La lámpara maravillosa no debe quedar fuera de la atención de los lingüistas.

s Desde luego, el ideal de los lingüistas no es el estudio diacrónico sin más, sino —nos 
El título de estas páginas está claro que se inspira en otro que se preguntaba si es posible hacer dialectologia estructural, cosa que - por supuesto- es posible y además empíricamente adecuada. Nosotros, con nuestro título, queremos decir que desde luego es posible emprender (aunque quizá sólo es tarea hacedera por varios conjuntamente) una Historia de las ideas lingüísticas en España, si bien habría que procurar saltar en lo posible por encima de varios errores e imperfecciones hasta ahora frecuentes.

En efecto, lo primero, que es la nómina de quienes han de ser estudiados, tenemos ya los suficientes datos como para saber que puede quedar mejor establecida de lo que está: autores como Damasio de Frías, Bartolomé José Gallardo, Larra, García de Diego (por su Lingüistica general y española), es más frecuente que sean preteridos que lo contrario ${ }^{6}$. Las valoraciones, por otra parte, tampoco parecen adecuadas muchas veces; nadie ignora a Correas, queremos creer, pero no es lo común que se destaque su relieve, ni incluso el de Aldrete. Se diria que se hace importantes más que nada a los autores cuyos textos es fácil ver en bibliotecas o conseguir en el mercado.

Autores y obras, además, precisan de una nueva lectura. Ni Nebrija —creemos nosotros- dice siempre lo que se le atribuye, ni Menéndez Pidal se queda nada más que en lo que se le suele conceder; textos como Poesia española de don Dámaso o Lenguaje y poesía de Jorge Guillén acaso no puedan entenderse en su raíz primera si se olvida que están escritas por autores de poemas puros y que son contemporáneos y coetáneos del formalismo ruso ${ }^{7}$.

Habrá de prestarse atención también -ya lo hemos dicho- a los ideales de estilo que se desprenden de algunos pasajes de las obras de gramática; esos pasajes o bien quedan desapercibidos, o se les desatiende, o no se les pone en relación con los hechos de la serie literaria española. Haría falta, por supuesto, que los estudiosos de la literatura leyesen a los gramáticos, pues quizá para ellos destaquen aspectos que a nosotros se nos escapan.

La historia no es crónica sólo, sino interpretación de los datos; así, no podremos quedarnos en el mero registro de esos datos, sino que habrá de llegarse a su interpretación, que en el caso de los hechos que antes llamábamos «externos» supone llegar hasta la historia cultural y

parece- la posible unicidad de sincronías y diacronia. Puede comp., por otro lado, Abad, 1983a: 13-26, 1983b, 1983c.

- Citamos estos nombres a modo sólo de ejemplo.

7 A título anecdótico diremos que la segunda de estas obras aparece citada a veces con el título - que por supuesto no tiene-Poesia y literatura. 
la «historia» sin más. La historia de cualesquiera ideas, y desde luego de las ideas lingüísticas, es historia institucional, politica, etc. ".

A estos que creemos requisitos de la historiografía de las concepciones sobre el lenguaje se ha atendido en muchas ocasiones, de modo parcial o más completo, pero pocas veces suficientemente; quizá una mayor consciencia de lo que se está haciendo cuando se trabaja y escribe sobre historia de las ideas lingüisticas se traduzca en la mayor calidad de los resultados. Y aunque parezca mentira, hay que lamentarse de que esos resultados salgan a veces no ya con erratas inevitables, sino hasta con faltas ortográficas; bien es verdad que hoy muchas veces no se pueden ver las pruebas, e incluso se intercalan párrafos de otra mano que la del autor, pero no por ello el hecho final es más presentable.

Del lado de los historiadores de la filosofía hay que decir que en distintas ocasiones incluyen también en su relato a las grandes figuras del pensamiento lingüístico, lo que supone un enriquecimiento; aunque desde su perspectiva profesional es inevitable que se les escapen cosas - como se les escapan a los filólogos cuando se ocupan de temas de ideas-, la verdad es que a veces la falta de información con que se trata a esas figuras es notoria. No decimos esto como crítica, sino en cuanto mera comprobación de un hecho.

Qué fueron los estudios lingüísticos en el Siglo de Oro español ha sido apuntado por Juan Miguel Lope Blanch con este párrafo:

"La aparición, en 1492, de la Gramática castellana de Nebrija marca el comienzo de una época — que habia de durar casi dos siglos-durante la cual la filología española alcanzó un esplendor nunca después proporcionalmente igualado. A lo largo de todo el siglo XVI y durante buena parte del XVII se imprimieron en España o en otros países de Europa y aun en América, multitud de libros en los que se estudiaba, con diversa metodología y vario propósito, la lengua española o los idiomas americanos recién descubiertos."

Las grandes figuras de esas centurias son, sin duda, Antonio de Nebrija, Bernardo de Aldrete y Gonzalo Correas, más un gramático

* Cfr. el fondo de razones que apunta Roldán, 1976, y comp. el estudio de José Maria López Piñero (1979). 
español aunque no hispanista como Francisco Sánchez el Brocense. Por supuesto muchos otros autores reclaman atención, empezando por el gran Juan de Valdés, y también los hay casi olvidados: no ya el aludido Damasio de Frías, sino un nombre importante como Juan Caramuel Lobkowitz".

Antonio de Nebrija —vamos a referirnos en primer término a él- es autor como se sabe de una primera gramática de la lengua romance castellana. Ya en el otoño y primeras semanas del invierno de 1486 presentó una muestra de la misma a la Reina Católica, pero Isabel, extrañada de la novedad del intento, se olvidó de él y encargó a Antonio hiciese una versión de sus Introductiones latinae que efectivamente fue impresa quizá en $1488^{10}$. La dedicatoria de esas Introducciones latinas está referida, como puede suponerse, a la importancia del conocimiento del latín, y asi Nebrija dice en ella:

«Para el colmo de nuestra felicidad i complimiento de todos los bienes ninguna otra cosa nos falta sino el conocimiento de la lengua, en que está no solamente fundada nuestra religión i república christiana, mas aun el derecho civil i canónico, por el qual los ombres viven igualmente en esta gran compañía que llamamos ciudad; la medicina, por la qual se contiene nuestra salud i vida; el conozimiento de todas las artes que dizen «de humanidad», porque son proprias del ombre en quanto ombre."

Nos encontramos, según advierte la crítica, ante un verdadero prólogo al Renacimiento español más que ante el mero prefacio a un libro. Vemos, en consecuencia, que la novedad de una gramática romance habia de llamar la atención, y por eso Nebrija hubo de poner por extenso las razones de la suya: la estimación coetánea primaba muy por encima las Introductiones latinae.

"Siempre la lengua - dice Antonio- fue compañera del imperio», queriendo exaltar el Estado y la Monarquía en que vive y recordando por ello los casos antiguos paralelos de esplendor monárquico y de las letras hebraico, griego y latino. Gozamos de una monarquía y paz, continúa dirigiéndose a la reina Isabel, «primeramente por la bondad y providencia divina; después, por la industria, trabajo y diligencia de

Q Que vivió entre 1606 y 1682. Sobre él hay un primer escrito de Juan Gutiérrez Cuadrado (1980).

10 Cfr. para todo esto y 10 que sigue Quilis, 1980; Rico, 1981, y Abad, 1982a y 1983d. Deploramos disentir en varias cosas de nuestro compañero citado en primer término. 
vuestra real Majestad; en la fortuna y buena dicha de la cual, los miembros y pedaços de España, que estavan por muchas partes derramados, se reduxeron y aiuntaron en un cuerpo y unidad de Reino, la forma y travazón del cual, assí está ordenada, que muchos siglos, injuria y tiempos no la podrán romper ni desatar»; «no queda ia otra cosa - concluye - sino que florezcan las artes de la paz". Éste resulta, pues, el primer motivo para "reduzir en artificio" el lenguaje castellano, el momento de esplendor monárquico-estatal que hace que la lengua se halle "en la cumbre»; "más se puede temer — por tanto- el decendimiento della que esperar la subida».

Segunda razón o motivo de provecho de reducir en artificio el idioma es «dar a los ombres de mi lengua obras en que mejor puedan emplear su ocio, que agora lo gastan leiendo novelas o istorias embueltas en mil mentiras y errores». Así mismo desea Nebrija "que lo que agora y de aqui adelante... se escriviere pueda quedar en un tenor, y estender se en toda la duración de los tiempos que están por venir, como vemos que se a hecho en la lengua griega y latina, las cuales por aver estado debaxo de arte, aun que sobre ellas an pasado muchos siglos, toda vía quedan en una uniformidad".

Aspira Antonio por igual a la gloria de haber sido «los primeros inventores de obra tan necessaria", y a que los hablantes castellanos que quieran estudiar gramática latina «después que sintieren bien el arte del castellano, lo cual no será mui dificile, por que es sobre la lengua que ia ellos sienten, cuando passaren al latín no avrá cosa tan escura que no se les haga mui ligera".

En fin, señala Nebrija un motivo más para haber compuesto su Gramática sobre la lengua castellana, y es el que unos años atrás habia apuntado "el mui reverendo padre Obispo de Avila»: "que después que vuestra Alteza metiesse debaxo de su iugo muchos pueblos bárbaros y naciones de peregrinas lenguas, y con el vencimiento aquellos ternían necessidad de recebir las leies quel vencedor pone al vencido, y con ellas nuestra lengua, entonces, por esta mi Arte, podrían venir en el conocimiento della, como agora nos otros deprendemos el arte de la gramática latina para deprender el latín». En efecto, “los enemigos de nuestra fe» "tienen ia necessidad de saber el lenguaje castellano», pues se encuentran "vencidos por guerra y fuerça de armas"; Antonio está aludiendo sin duda —aunque esto no suele interpretarse asi- a la capitulación de Granada que se concertó el anterior 25 de noviembre, a la rendición de la ciudad el 2 de enero del mismo 1492 y a la entrada inmediata en ella el día 6.

La necesidad - por tanto- de que los enemigos de la fe ya vencidos aprendiesen el idioma castellano, más otras distintas razones, em- 
pezando por la de que la lengua siempre ha sido compañera de la Monarquía y el Estado, constituyen el conjunto de motivos que Nebrija hace concurrir como motivo de la insólita empresa de escribir una gramática de la lengua vulgar castellana.

Las obras y los documentos literarios -dicho queda- nos dan a conocer también ideas lingüisticas que forman parte de las poéticas sucesivas de la serie artística y a las que, por tanto, habrá de atenderse. A título de ilustración nos referimos ahora al Arte nuevo lopeveguesco ".

Entre los versos 246 y 318 del mismo, efectivamente, se encuentran las ideas de Lope en cuanto a lengua, métrica y figuras retóricas, ideas presididas siempre por un designio de «decoro» (correspondencia entre la cualidad del personaje y su comportamiento y hablar) y -en definitiva- de verosimilitud general.

En conjunto dice Lope que la comedia ha de imitar la lengua nítida y fácil de las ocasiones ordinarias, una lengua nada afectada:

con lenguaje casto

no gaste pensamientos ni conceptos

en las cosas domésticas, que sólo

ha de imitar de dos o tres la plática.

... Dionos ejemplo Arístides retórico, porque quiere que el cómico lenguaje sea puro, claro, fácil, y aún añade que se tome del uso de la gente, ... Si ha de imitar a los que hablan, no ha de ser por Pancayas, por Metauros, hipogrifos, semones y centauros.

No obstante, ha de ser utilizado un registro idiomático distinto cuando el discurso es persuasorio, de disuasión o de consejo, para así seguir imitando la verdad; entonces ha de haber sentencias y conceptos:

Mas cuando la persona que introduce persüade, aconseja o disüade,

1 Glosamos la bibliografia reciente en torno al poema en 1983a (pp. 191-196). 
alli ha de haber sentencias y conceptos, porque se imita la verdad sin duda, pues habla un hombre en diferente estilo del que tiene vulgar, cuando aconseja, persüade o aparta alguna cosa.

Se refiere luego el dramaturgo madrileño a los diversos niveles de habla que corresponden a los personajes según el decoro poético: el rey ha de manifestarse con gravedad imitada en cuanto sea posible, el padre con sentenciosidad o doctrina, el galán y la dama con afectos, subjetivamente, y -en fin- el gracioso, expresando cosas llanas en idioma también llano:

Si hablare el rey, imite cuanto pueda

la gravedad real; si el viejo hablare, procure una modestia sentenciosa; describa los amantes con afectos que muevan con extremo a quien escucha;

... El lacayo no trate cosas altas, ni diga los conceptos que hemos visto en algunas comedias extranjeras.

Debe darse asimismo lo que podríamos llamar «decoro métrico", esto es, adecuación entre lo que pasa en escena y las formas métricas que lo expresan. La verosimilitud buscada -entre otras cosas- lleva a la comedia a la polimetría, pero no se trata de una polimetría sin más, sino correspondiente (pide Lope) a las sustancias de contenido:

Acomode los versos con prudencia a los sujetos de que va tratando. Las décimas son buenas para quejas; el soneto está bien en los que aguardan; las relaciones piden los romances, aunque en octavas lucen por extremo. Son los tercetos para cosas graves, y para las de amor, las redondillas.

Las formas métricas, en efecto, parecen escogidas en virtud de la adecuación que les prestan su propia textura o forma y la tradición literaria de su uso. Destina Lope en general décimas, sonetos y tercetos para el razonamiento y los momentos graves o elevados, las redondillas para el hablar amoroso ordinario, y los romances y octavas para la 
narración, sencilla o elevada; se trata, como decimos, de formas escogidas por su adecuación formal o tradicional a unos determinados contenidos.

Estas formas deseadas han de ser tenidas a modo de "canon métrico" institucional, es decir, de formas que se estiman adecuadas para el decoro y verosimilitud de la comedia; interesan, por tanto, como manifestación de una conciencia idiomática. Tarea de la historia literaria será establecer en qué medida el propio Lope acomodó su escritura al canon que estableció; en cualquier caso, no debe escandalizar mucho que no siempre lo siguiese, pues aparte su valor meramente general, historia es siempre tanto cumplimiento como transgresión de las instituciones y cánones.

Por último, señala el madrileño que importan las figuras retóricas, y menciona varias en general usadas por él en sus decursos dramáticos:
Las figuras retóricas importan, como repetición o anadiplosis; y en el principio de los mismos versos aquellas relaciones de la anáfora, las ironías y adubitaciones, apóstrofes también y exclamaciones.

Ideas, pues, como las expresadas por Lope en el Arte nuevo, o como las de Boscán en su Carta a la duquesa de Soma y Cervantes en el Quijote o la Novela y coloquio que pasó entre Cipión y Berganza (testimonios mayores respecto a la poesía, la novela y el teatro modernos españoles) habrán de tenerse en cuenta no olvidándolas, así como habrán de ser manejadas operativamente al trazar de verdad la historia de nuestra lengua literaria ${ }^{12}$.

Ilustradas, a modo de testimonio, algunas concepciones idiomáticas de Nebrija y de Lope de Vega, vamos a referirnos ahora a las del padre Martín Sarmiento, en cuanto muestra de las ideas lingüisticas españolas de los siglos más recientes ${ }^{13}$.

Empieza Fray Martín por creer que el origen de los idiomas se halla

12 Comp. Abad, 1983a: 72-85.

13 Ctr. otra sintesis en Pensado, 1960. Como ejemplo de las novedades que aún puede descubrir la investigación en historia de las ideas idiomáticas, Yllera, 1983. 
en el remedo que de sonidos naturales han hecho los bárbaros y los niños: «Tengo por misterio - escribe- el origen de las lenguas y creo que, o Dios las infundió por Sí mismo, o que, si han tenido algún origen sublunar no se debe buscar sino en los bárbaros y en los niños, que más hablan remedando sonidos naturales que no inventando voces ad placitum»; "mi sistema del origen de las lenguas - dice en otro momento- no es ad placitum ni de capricho, sino naturalísimo y fundado en la misma naturaleza de las voces o sonidos que naturalmente profieren los vivientes, y entrando ante todos el hombre con sus interjecciones, que todas son naturales». No obstante, parecería el padre Sarmiento querer subrayar también la arbitrariedad del idioma, y dice por ello: «Zape se inventó para espantar a los gatos y miz para atraerlos, y yo sé de uno que los atraía con zape y los espantaba con miz"; de ahí igualmente que no se vea "cuál es aquella singularidad del castellano en significar con más propiedad sus cosas, que no tenga otro cualquier idioma».

Percibe asimismo Fray Martín Sarmiento perfectamente el hecho de la diferenciación o dialectalidad interior de las lenguas, cómo la fonética se halla escindida según comarcas y regiones: «Es quimera - nota- que todas las naciones del mundo puedan concordar en pronunciar tales y tales letras de un mismo modo; aun dentro de una nación sucede esto entre diferentes territorios. A diez leguas que disten entre sí estos países, aun usando de la misma lengua, no concuerdan, en la pronunciación, no sólo de una dicción, pero ni de tal y tal letras, ni del acento o tonillo". Dialectos resultan gallego y castellano del latín; nuestro autor barrunta nítidamente la fonética románica, y se expresa con este razonamiento global:

"Tardé poco en observar que la lengua gallega y la castellana no son sino dos dialectos de la lengua latina en toda su extensión, y que cuanto más se retrocede en siglos casi coinciden esos dos dialectos... Antes de los godos la analogía y alteración de las letras latinas era uniforme en los dos dialectos. Después, con el tiempo, el dialecto castellano se apropió una especial analogía, y el gallego no quiso mudar la suya por ser tan tenaz. No hay cosa más vulgarizada que el decir que el puro idioma castellano es una corrupción de la lengua latina, y que el puro gallego es una corrupción de la lengua castellana. Son dos errores vulgares y errada inteligencia de la voz corrupción en materia de lenguas, confundiendo la analogia con la corrupción. El castellano paulatinamente se fue formando del latín a los principios, pues las dos naciones hablan un mismo latín, guardando siempre la analogia de las letras. Lo mismo digo del gallego, pero jamás el gallego se ha formado del castellano." 
Fray Martín sabe también cómo las lenguas de Italia, la francesa y la «lemosina» no son sino dialectos del idioma romano, y - concordantemente - considera épocas y estados que va teniendo la lengua latina, el visigótico español, el posterior desde «la pérdida de España» a "la unión de Castilla, Galicia y León en don Fernando el Magno", más luego los sucesivos de predominio castellano.

El ámbito hispanohablante peninsular consta, define, de «dialecto castellano" más "todas las voces que se usan en las provincias»; junto lo uno y lo otro dan lugar a la lengua "española». Castellano o cualquier código idiomático se explican y entienden a la luz etimológica: «Yo miro el estudio de las etimologías — dice el Padre Sarmientocomo la raíz y base fundamental para entender, penetrar y comprender el origen de las mismas voces que hablo y que antes sólo hablaba como un papagayo".

El método etimológico consiste en reducir a un sistema de reglas fijas las alteraciones y transformaciones constantes que padecen cestas o las otras letras, cuando pasan de un labio a otro para pronunciarse"; luego, "concurriendo la analogía de las letras y la identidad del significado se hace evidencia matemática que la etimología es evidente", si bien una completa etimología debe constar de “la historia cronológica de la voz y sus traslaciones metafóricas» más «la historia de la cosa y de sus propiedades", es decir, de estudio de la palabra y de la cosa.

Fray Martín apunta -entre imperfecciones inevitables- casos de tránsitos del latín al vulgar, esto es, «elementos etimológicos», algunos de los cuales (referidos al castellano) son éstos ${ }^{14}$ :

B del latín P: Cabra, de Capra. Biznaga, de Pastinaca. Cabeza, de Capita. Enebro, de Juniperc $B$ de Ph: Esteban, de Stephanus. $B$ de F: Ábrego, de Africo. B de V: Boda, de Vota. Ch de Cl: Cuchara, de Coclear. Ch de Fl: Inchar, de Inflare. Ch de Pl: Ancho, de Amplo. Cacha, de Capulum. Ch de Ct: Noche, de Nocte. Ch de Lt: Mucho, de Multum. $D$ de T: Higado, de Ficatum. G de C: Domingo, de Dominicus. Gato, de Catus. Mendigo, de Mendicus. $H$ de F: Harina, de Farina. Hue de $O$ : Huebra, de Opera. $H$ de G: Hermano, de Germano. L de R: Peligro, de Periculo. LI de Pl: Llegar, de Plicare. LI de Cl: Llamar, de Clamare. LI de Bl: Trillo, de Tribulo. Ll de Fl: Llamas, de Flammas. M de V: Mimbre, de Vimen. $\tilde{N}$ de $N n$ : Año, de Annus. $\tilde{N}$ de Gn: Señas, de Signa. $\tilde{N}$ de $M n$ :

14 Los damos siempre según los tomamos literalmente del padre Sarmiento. 
Daño, de Damnum. $\tilde{N}$ de Nea: Viña, de Vinea. $\tilde{N}$ de Nia: España, de Hispania. X de S: Xabon, de Sapone. Z de S: Zampoña, de Symphonia. $Z$ de Que: Lazo, de Laqueo. $Z$ de Tu, Te: Pozo, de Puteo. Solaz, de Solatium. $Z$ de Pt: Cazar, de Captare. $Z$ de Ci: Lizo, de Licium. $Z$ de Di: Gozo, de Gaudio. E de A: Dinero, de Denario. E de 1: Concejo, de Concilio. I de E: Avispa, de Vespa. le de E: Miedo, de Metus. Ye de E: Yermo, de Eremo. O de U: Lobo, de Lupus. O de Au: Oro, de Auro. Ue de O: Fuente, de Fonte. La consonante $D$ se pierde entre dos vocales: Rayo, de Radius. Caer, de Cadere. La consonante $G$ se pierde entre dos vocales: Vaina, de Vagina. La consonante $B$ se pierde antes de $\mathrm{M}: \mathrm{Co}-$ loma, de Columba. La consonante $C$ se pierde antes de $T$ : Hito, de Fictum. La consonante $P$ se pierde antes de $T$ : Siete, de Septem. La consonante $N$ se pierde entre dos vocales: Asa, de Ansa. La vocal / se pierde entre dos consonantes: Domingo, de Dominicus. La vocal $U$ se pierde entre $C$ y $L$ : Ojo, de Oculus. $A$ se añade al principio: Azufre, de Sulphur. $B$ se añade al medio entre $M$ y $N$ : Hombre, de Homine. $B$ se añade en el medio entre $M$ y $R$ : Hombro, de Humerus. $E$ se añade al principio ante $S$ liquida: Esmeralda, de Smaragdus. $R$ se añade: Estrella, de Stella.

Los tiempos más modernos cuentan en la historia de las ideas lingüisticas en España con figuras de interés y atractivo como la del padre Martín Sarmiento; otras no suelen estar incorporadas a la nómina conocida de autores, y esperan todavía que se les preste atención desde tal perspectiva: Francisco de Paula Canalejas, incluso Martinez Marina, etc. Desde luego, Bello, aunque naciese en Venezuela y sólo llegase a vivir en Londres y Chile, bien puede incorporarse a la serie de las doctrinas idiomáticas españolas, tanto por su altura eminente como por su huella en ellas; Bello es, así entendido, un "gramático español».

No obstante, vamos a referirnos en algunos párrafos a Unamuno, otro techo de las letras españolas e hispanas que sin embargo aún no ha encontrado quizá estudiosos suficientes de su talla: ni están sus obras completas en el mercado, ni tiene dedicada una obra sintética y de conjunto que comprenda a la vez lo filosófico y lo literario, ni muchos de sus textos parecen haber recibido una lectura e interpretación adecuada ${ }^{15}$. Nada digamos de la intelectualidad integrista, que derechamente lo tiene tachado y sólo reconoce como pensadores de talla

15. El mejor estudio de los existentes sobre don Miguel es el de Carlos Paris (1968). Aspectos más sombríos de los escritores del novetayocho apunta José Luis Abellán (1973). 
contemporáneos a Amor Ruibal, D'Ors, Ortega, Zubiri y Antonio Millán Puelles, en exclusión que se comenta por sí sola ${ }^{16}$.

Vamos a destacar alguna de las ideas filológicas de don Miguel ${ }^{17}, y$ lo hacemos refiriéndonos en primer término a su mentalidad positivista ${ }^{18}$. Trata Unamuno en 1894 de los resultados del aprendizaje del proceso formativo del castellano, y escribe:

«A partir de hechos fácil e inmediatamente asequibles, de la lengua misma que habla, se ejercitaría al alumno en el saludable rigor del método inductivo... Iria a la vez aprendiendo el alumno a sujetarse a los hechos, a los hechos vivos, a buscar en ellos mismos su razón de ser, a comprender que la ciencia exige saber observar, tener paciencia y esperar a que las cosas se expliquen a si mismas, sin forzarlas; a penetrarse sobre todo de esta verdad tan desconocida: que la ley no es cosa distinta del hecho. Aprendería a no deformar los hechos para plegarlos a sus ideas, sino éstas a aquéllos... Además de todo esto, los principios de la evolución orgánica, la lucha por la vida..., etc., todo ello se ve en la lingüística con menos trabajo que en la botánica o en la zoología, porque se dispone más a mano de elementos más manejables."

Don Miguel, pues, identifica el conocer científico con los hechos mismos, y así insiste otra vez proclamando que la ley «no es cosa que se distinga realmente de los hechos mismos, sino la generalización de éstos". Nueve años después ejemplifica donosamente las leyes naturales de la lucha por la subsistencia, la selección del más apto y la atrofia del órgano sin función; lo hace así: «Los Fulánez, en efecto, están llamados a desaparecer gradualmente, reduciéndose antes a iniciales. Un Dominguez y Bécquer suprime la y y hace apellido compuesto; su hijo reduce el Domínguez a D., órgano sin función, mero pendejo orgánico, como los dedos superiores del toro, y luego ese órgano acaba por desaparecer. $Y$ asi tenemos al poeta Bécquer, que era un Domínguez liso y llano. Si en Alemania naciese un Bécquer Domínguez, es lo más fácil que se quedara en B. Domínguez».

En cualquier caso, Unamuno pide una "verdadera etimología», es decir, aquella que se ocupa no sólo de las alteraciones de los sonidos y las formas, sino que asimismo estudia «el proceso de significación de un vocablo, su semiótica", la evolución del sentido. Pide también una gramática del castellano sin forzados esquemas latinizantes, según

16 La hace Gonzalo Fernández de la Mora (1983: 36).

17 Sobre ellas comp. -entre otras cosas- Garcia Blanco (1952).

is En general, vid. Jover, 1974. Hay buena bibliografía posterior, como se sabe. 
quiso hacer - señala - don Andrés Bello en su «monumento admirable" Gramática de la lengua castellana, y en el mismo orden de ideas advierte perfectamente la sencillez del sistema fonético español y la estabilidad idiomática que de ella se deriva: la lengua hispánica, dice, compartirá un dia con la inglesa el predominio mundial; "la simplicidad de su fonética, su misma pobreza de sonidos, le da una resistencia y una fijeza grandes. Es muy difícil deformarla hasta hacerla ininteligible, por muy mal que se la pronuncie».

En efecto, Unamuno propugnó siempre un idioma que fuese hispánico, "sobrecastellano" en cuanto integrador de hablas diferenciadas: "La cuestión - proclama - es que los argentinos y todos los demás pueblos de habla española reivindiquen su derecho a influir en el progreso de la común lengua española tanto como los castellanos mismos... Al adoptar el castellano, el idioma de setenta y tantos millones de hombres, no debemos resignarnos a adoptarlo pasivamente, plegándonos en todo y por todo a las exigencias de los castellanos, sino que hemos de tirar a infundir en él nuestro espíritu, a hablarlo a nuestro modo, siempre que nos demos a entender de todos los que lo hablan, a acelerar su vida". Diez años más tarde insiste en que la lengua constituye el patrimonio principal de los pueblos hispanos, a cuya vida deben contribuir todos sin monopolio de ninguno de ellos, y todavía - por ejemplo- ocho años después (en 1919) estampa esta bella sugerencia: “Valiera más - dice en referencia al 12 de Octubre-, que en vez de Fiesta de la Raza se le llamase Fiesta de la Lengua, y que en ella se celebrase lo que durante el año se haya hecho por mantener la unidad y a la vez la variedad de nuestro común lenguaje, por enriquecerlo con la integración de las distintas modalidades que de él se produzcan en los vastos dominios de la veintena de naciones -incluyo a España y Filipinas- en que se habla y por el conocimiento mutuo de los ingenios que en ellas florezcan».

Asimismo se encuentra en don Miguel la idea de lo que se ha llamado "la lengua como libertad», esto es, la idea de la libertad y necesidad lingüisticas. "Sólo un límite —escribe en 1903- tiene la libertad lingüistica, y límite libre en cuanto es, más bien que impuesto, nacido de la necesidad de las cosas. Este límite es la inteligibilidad de lo que se dice"; el que se empeñe en lo contrario, tenía dicho ya, en su pecado llevará la penitencia. Un idioma, pues, nos pone el mero limite de que más allá de su código ya no somos inteligibles, pero desde luego nos deja, según nuestras capacidades, hacer un discurso personalmente modulado ${ }^{14}$. A esta libertad se refiere Unamuno, entendiéndola de varias maneras.

19 Comp. las páginas primeras de Abad, 1984b. 
Libertad lingüística significa, en primer término, contenido incitante: "Escribe como te dé la real gana, y si dices algo de gusto o de provecho y te lo entienden y con ello no cansas, bien escrito está como esté; pero si no dices cosa que lo valga o aburres, por castizo que se te repute, escribes muy mal». También supone libertad la elección estilística y, dentro de ella, el etimologismo: "Lo importante es darnos cuenta del habla en que encarnamos nuestra ideación, hacérnosla consciente y reflexiva. Porque tal debe ser el intento de quien escriba: convertir el vocablo, mediante reflexión, en algo de que tengamos plena conciencia, sacándolo de ser lo que en el lenguaje hablado y automático es: un mero reflejo... El conocimiento del proceso vital de nuestro idioma castellano y de cómo éste se ha ido constituyendo a partir del latín vulgar, ha de ayudarnos para renovarlo y vivificarlo»; las lenguas, en definitiva, «viven de herejias».

La dialectalidad interna del lenguaje llega hasta el idiolecto personal: «Cada uno de nosotros, cuando es él, y no un cacho de muchedumbre, tiene su habla propia, que está creando y recreando de continuo»; el idioma nos da asimismo el pensamiento, sostiene Unamuno idealistamente: “Dar nombre a las cosas, como hizo Adán, es conocerlas y apropiárselas. El nombramiento es el acto de posesión espiritual... Nombrar es conocer, y para nosotros es hacer la cosa, hacérnosla".

Los postulados y ejemplos que han dado lugar a estas páginas tratan de sugerir cuál es el estado y necesidades de la Historia de las ideas lingüísticas como disciplina, en referencia concreta al caso español. Habrá de estar atendida la sucesión de ideaciones sobre el lenguaje, esto es, el sucederse conceptual de la ciencia idiomática, más el sentido de historia y de cultura que tenga tal devenir. Por lo demás, tanto la nómina de autores considerados como su valoración respectiva deberán quedar reajustadas, y asimismo la "lectura» de los mismos. La historia de las ideas lingüisticas, en fin, deberá estar abierta a sus dos disciplinas secantes, la Historia de la lengua y la Historia del idioma literario.

Podrá parecer sorprendente que a la altura de nuestros dias aún se reclame en parte una historiografía "de las grandes figuras", pero en verdad el estado de cosas lo hace necesario: ni siempre parece tenerse en claro cuáles son, ni a veces sus textos resultan accesibles, ni - sobre todo- parecen bien leidas e interpretadas.

Citarse a si mismo puede ser tomado por un pecado de onanismo; se cierra uno a las perspectivas enriquecedoras de los demás - ya que 
en definitiva entre todos sabemos las cosas que sabemos--, y parece uno querer permanecer en sus propios y parciales hallazgos. No obstante, y dado que este trabajo ha sido concebido como especie de prefacio (o conclusión) a una *Pequeña historia de las ideas lingüisticas en España que como tal no tenemos hecha pero si en buena parte escrita, nos permitimos enumerar las distintas páginas a las que las presentes pueden prestar unidad global; son éstas -aparte otros escritos a los que no hacemos referencia-: Abad, 1980a, 1980b, 1982a, 1982b, 1983d, 1983e, 1983f, 1983g, 1984a, en prensa.

\section{Referencias Bibliográficas}

Abad, Francisco (1980a), «Problemas de historiografía de la Lingüística», «Menéndez Pidal en la Historia de las mentalidades»y "La obra filológica del Centro de Estudios históricos", en Estudios Filológicos, Valladolid, Universidad.

- (1980b), Lengua española e historia de la lingüistica (Primer estudio sobre Andrés Bello), Madrid, SGEL.

- (1982a), "Nebrija ante Juan de Mena», en Los géneros literarios y otros estudios de Filologia, Madrid, Egartorre, pp. 140-143.

- (1982b), "ldea de las categorías gramaticales en Andrés Bello», en Los géneros..., pp. 22-34.

- (1983a), Caracterización de la Literatura española y otros estudios, Madrid, Tapia.

- (1983b), "Las disciplinas lingüísticas", en Presentación de la Lingüistica contemporánea y otros estudios, Málaga, EDAF, pp. 11-23.

- (1983c), «Hacia una historia de la lengua literaria», en Serta philologica F. Lázaro Carreter, Madrid, Cátedra, i, pp. 1-9.

- (1983d), “Gramáticos españoles», en Noticia de la lengua española, Madrid, EDAF, pp. 55-89.

- (1983e), «El principio gramatical de Andrés Bello», en Caracterización..., pp. 197-200.

- (1983f), «La 'Historia de la Lingüística' como disciplina», en Presentación..., pp. 25-43.

- (983g), “Ortega ante el lenguaje», en Ínsula, 440-441, pp. 13 y 16.

- (1984a), «El 'Diálogo de las lenguas' de Damasio de Frías», en la parte segunda de Conceptos de Crítica literaria, Madrid, Istmo. 
- (1984b), «Sobre la lengua y el estilo: Valle Inclán», en El Crotalón, 1.

- (en prensa), "Gramáticos españoles no hispanistas (San Isidoro, El Brocense)», en Homenaje a José Antonio Maravall, Madrid.

- (en prensa), "Las ideas lingüísticas en la Modernidad española: Juan de Valdés, Bernardo de Aldrete, la Academia», en Homenaje a Pedro Sáinz Rodriguez, Madrid.

- (en prensa), «Ideas para una interpretación de Menéndez Pidal», en Homenaje a Manuel Sanchis Guarner, Valencia.

Abellán, José Luis (1973), Sociologia del 98, Barcelona, Península.

Fernández de la Mora, Gonzalo (1983), «La inteligencia según Zubiri», en Razón Española, 1, pp. 7-36.

Garcia Blanco, Manuel (1952), «Don Miguel de Unamuno y la lengua española", en La lengua española en la época de Carlos V. Madrid, 1967, Escelicer, pp. 69-131.

Gutiérrez Cuadrado, Juan (1980), «Juan Caramuel y su teorema fundamental», en L/ull, 3/1, pp. 39-108.

Jover, José Maria (1974), “Visión sinóptica de la cultura del positivismo", en P. Laín, dir., Historia universal de la Medicina, VI, Barcelona, Salvat, pp. 1-9.

López Piñero, José María (1979), Ciencia y técnica en la sociedad española de los siglos XVI y XVII, Barcelona, Labor.

Paris, Carlos (1968), Unamuno. Estructura de su mundo intelectual, Barcelona, Peninsula.

Pensado, José Luis (1960), Fray Martín Sarmiento: sus ideas lingüisticas, Oviedo, Universidad.

Quilis, Antonio (1980), ed. y estudio de A. de Nebrija, Gramática de la lengua castellana, Madrid, Editora Nacional.

Rico, Francisco (1981), "Un prólogo al Renacimiento español», en P. Piñero-R. Reyes, eds., Seis lecciones sobre la España de los Siglos de Oro, Sevilla, Universidad, pp. 59-94.

Roldán, Antonio (1976), "Motivaciones para el estudio del español en las gramáticas del siglo XVI», en RFE, LVIII, pp. 201-229.

Viñaza, Conde de la (1893), Biblioteca histórica de la filologia casteIlana, Madrid, Manuel Tello.

Yllera, Alicia (1983), «La gramática racional castellana en el siglo XVII: la herencia del Brocense en España», en Serta..., pp. 649-666. 